\title{
EFFECT OF E-PRESCRIBING IMPLEMENTATION ON REDUCING MEDICATION ERROR IN HOSPITAL
}

\author{
Akhmad Safi'i, Anhari Achadi \\ Hospital Administration Study, Faculty of Public Health, Universitas Indonesia
}

\begin{abstract}
Background: Medication error (ME) is a failure in the treatment process that can harm and endanger patient safety. One of the causes of ME is error in prescribing. Several studies have shown that electronic prescribing (e-Prescribing) is beneficial in reducing prescribing errors and improving patient safety. This study aimed to determine the effect of e-Prescribing in reducing ME.

Subjects and Method: This was a systematic review study. The keywords used in this study were "implementation" AND "electronic prescribing" AND "hospital". The articles were obtained from PubMed and Google Scholar. The articles were selected from 2015 to 2019, in English and Indonesian languages, full text, hospital setting area, and evaluate about implementation E-Prescribing in Hospital. The data were collected and analyzed based on PRISMA flow diagram.

Results: A total of $\mathbf{1 1}$ out of 27 articles were reviewed for this study. Nine articles stated that the impact of implementing e-Prescribing were to reduce ME, facilitate prescription services, process data input faster, and increase the effectiveness of communication between pharmacist and doctor. One article showed a non-significant changes after the implementation of the e-Prescribing, although it is encourages certain types of errors and mitigates others. While the other article discussed recommendation in implementing e-Prescribing, such as increased coordination between users, modification and flexibility of the hospital information system, optimizing systems from the outset, how expertise should be developed as well as increased learning by experience.

Conclusion: Implementation of e-Prescribing can reduce medication errors so that it has a positive impact on patient safety.
\end{abstract}

Keywords: implementation, electronic prescribing, medication error, hospital

\section{Correspondence:}

Akhmad Safi'i. Hospital Administration Study, Faculty of Public Health, Universitas Indonesia, Depok, Indonesia. Email: safii23bpjsjakbar@gmail.com. Mobile: 0857268-94350.

\section{BACKGROUND}

The practice of medicine in the world is not as safe as we would like it to be. There were around 44,000 up to 98,000 patients died in hospitals each year due to preventable medication error. It is estimated that medication error (ME) is responsible for one out of every 854 deaths in inpatients, and around 7,000 deaths occurred each year (Hinojosa-Amaya et al., 2016)

Medication error is a main problem that often occurs in practicums and hospitals. These errors are caused by prescription errors and prescribing error due to incorrect medical decision. Prescription error was the main cause $(70 \%)$ which affected patient safety and health quality (Farida et al., 2017). One of the factors causing prescribing errors is the doctor's handwriting on prescription paper that is difficult to read and the use of nonstandard abbreviations in writing prescription. It has the potential to endanger patient safety. In addition, it can lead to the substandard patient care. Therefore, efforts are needed to prevent prescription error, such as e-Prescribing writing in order to improve service quality and patient safety (Farida et al., 2017).

Based on a study regarding semi-structured face-to-face qualitative interviews, the implementation of e-Prescribing is recommended to improve patient safety and com- 
munication between doctors and discharge patients.

A total of 19 hospital staff including doctors, nurses, and pharmacists participated in this study. The result affected behavioral changes in the communication patterns of doctors' in discharge patients with the best quality information (Mills et al., 2017b).

Meanwhile, based on the observational studies and semi-interviews on pharmacist activities in the ward, pharmacists spent less time with patients after the implementation of e-prescribing (EP), valued patient safety more, and showed a level of resilience in ensuring an increased role of pharmacists in the prevention of ME (Mcleod et al., 2019).

The implementation of EP can also support or evaluate anti-microbial management activities both safety and quality (Micallef et al., 2017). Based on a Quasi Experimental study conducted in the United Kingdom, the implementation of EP could improve the quality of documentation of discharge and reduce prescribing error and types of changes in prescribing error (Mills et al., 2017a).

The EP in a German hospital uses an interdisciplinary approach in chronic drug reconciliation. Drug reconciliation reached $98 \%$ inpatients. It showed that there was only
1.3\% ME in patients (Villamayor-Blanco et al., 2016).

This study aimed to determine the effect of implementing e-Prescribing in reducing Medication Error in hospital, as well as providing recommendations to the stakeholders in hospitals.

\section{SUBJECTS AND METHOD \\ 1. Study Design}

This was a systematic review study. The keywords used in this study were "Implementation" AND "Electronic Prescribing" AND "Hospital". The articles were obtained from PubMed and Google Scholar. There were 258 articles from PubMed and 157 articles from Google Scholar. The authors conducted screening by excluding the same articles (313 articles). There were 27 articles found after screening based on inclusion and exclusion criteria. From the 27 articles, there were 11 articles that were suitable with the study of The Implementation of EP in Hospital.

\section{Inclusion and exclusion criteria}

The inclusion criteria of the articles were from 2015 to 2019, using English and Indonesian languages, full text, in hospital setting area, and evaluate about the implementation of E-Prescribing in Hospital. 


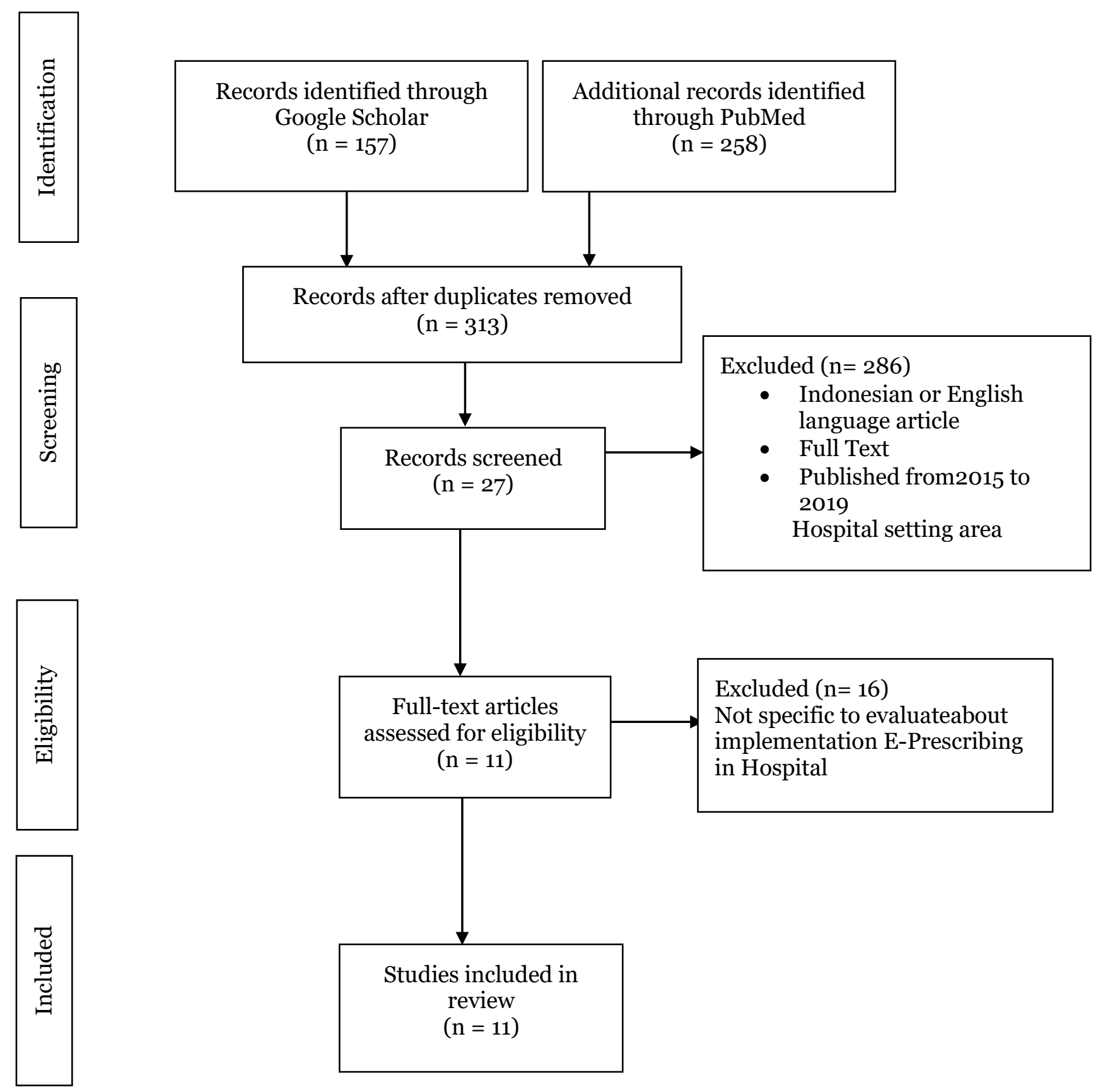

Figure 1. PRISMA Flow Diagram

\section{RESULTS}

Based on 27 articles that have been through the screening process, there were 11 articles that would be reviewed; 2 articles from the BMC Health Services Research Journal. 9 other journals can be seen in Table 1. 
Table 1. The journal reviewed

\begin{tabular}{cll}
\hline No & Journal & Amount \\
\hline 1 & BMC Health Services Research & 2 \\
2 & E-Journal Kedokteran Indonesia & 1 \\
3 & European Journal of Clinical Pharmacology & 1 \\
4 & Farmacia hospitalaria & 1 \\
5 & International Journal of Clinical Pharmacy & 1 \\
6 & Journal of Evaluation in Clinical Practice & 1 \\
7 & Journal of Innovation in Health Informatics & 1 \\
8 & AITA: Jurnal Informatika & 1 \\
9 & Jurnal Teknologi Informasi Universitas Lambung & 1 \\
& Mangkurat (JULM) & 1 \\
\hline
\end{tabular}

Based on 11 articles that were reviewed based on the study design, there were three articles with Qualitative design, two other articles with Observation design, 6 other articles with Mixed Method (Qualitative \& Quantitative),
Literature Review, Cross-Sectional, Practical Application Discussion, Experimental and Quasi Experimental. More detailed information can be seen in Table 1 .

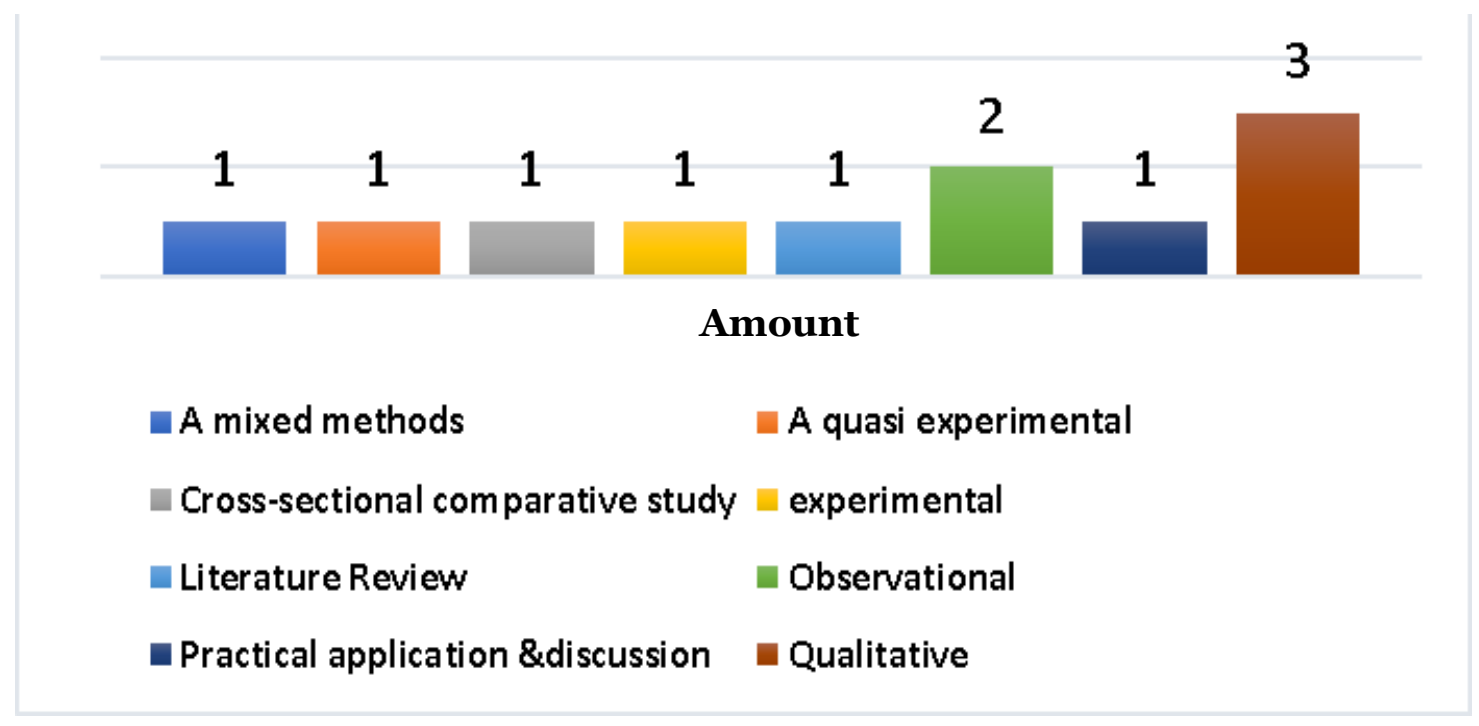

Figure 1.The Distribution of Articles' Study Design 
Table 1.The result of the article extraction

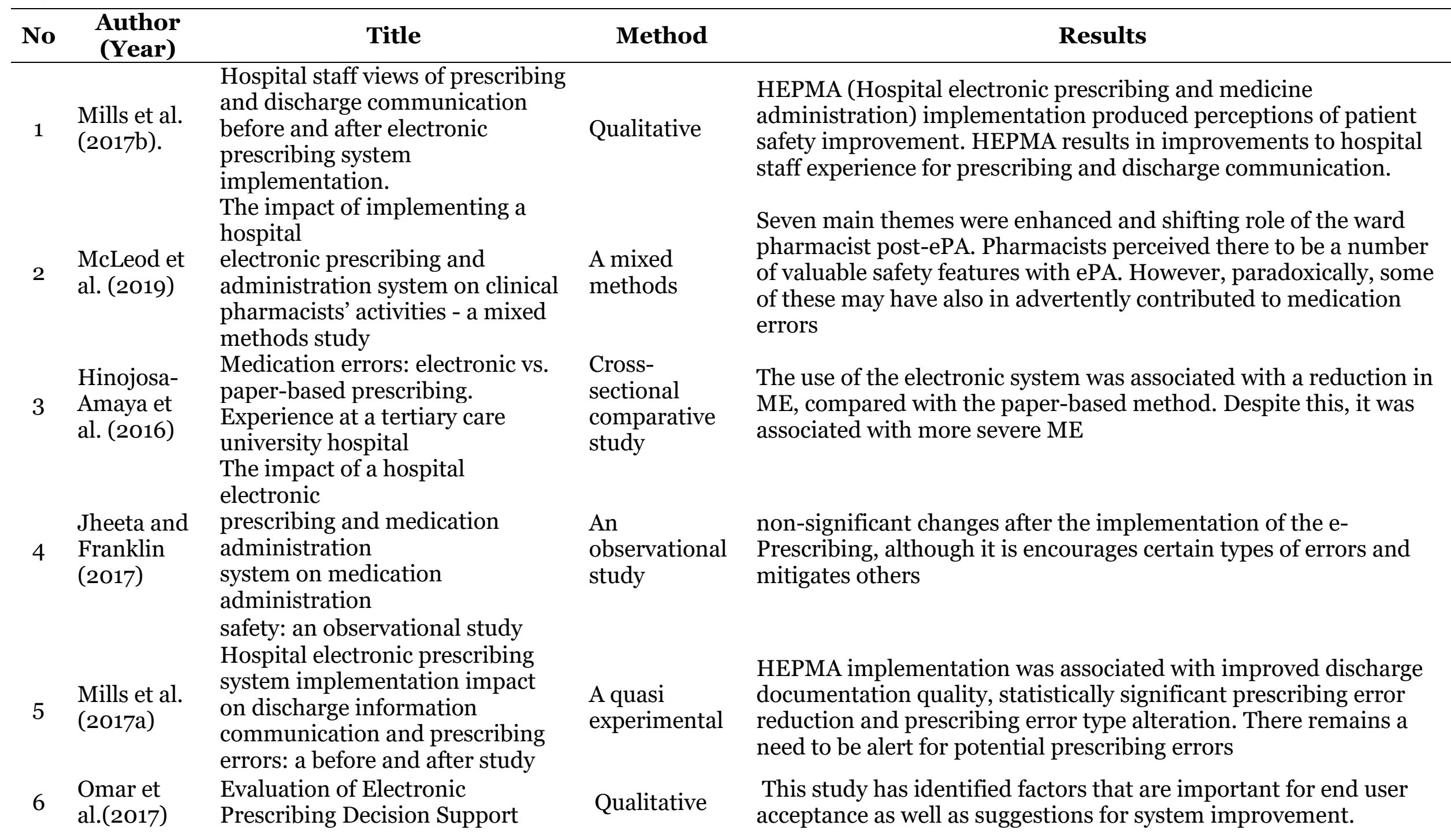

The $6^{\text {th }}$ International Conference on Public Health Best Western Premier Hotel, Solo, Indonesia, October 23-24, 2019 | 224 https://doi.org/10.26911/the6thicph-FP.04.01 
System at a Tertiary Care Pediatric Hospital: The User Acceptance Perspective.

Five key recommendations for the implementation of hospital electronic

7 et al (2016) prescribing and medicines administration systems in Scotland

Lucia

8 Villamayor

Blanco et

al. (2016)

Medicines reconciliation at

hospital admission into an electronic prescribing program

Farida et

Implementation of Electronic al. (2017) Prescribing (at RSCM)

Alfah and

10 Megariani

(2002)

Arifin and

E-Prescribing and Barcode System for Prescription Drugs in Hospital (Pertamina Tanjung Hospital, South Kalimantan)

11 Dirgahayu, (2017)
The evaluation of the implementation of E-Prescribing Modul in hospital with Pieces Method (RSUP Dr. Sardjito)

Although pediatricians are positive to the usefulness of Electronic Prescribing Decision Support Systems ( EPDSS), it appears there are some acceptance problems due to ease of use concern and usability issues of the system

Practical Application and Discussion

An

Observational study

Literature Review

Experimental

Qualitative
Five key aspects of deployment strategy: 1) the way central coordination should be conceptualized, 2) how flexibility in strategy can be ensured, 3) paying attention to optimizing systems from the outset, 4) how expertise should be developed and centrally shared, and 5) ways in which learning from experience can be maximized.

Using an electronic prescribing program and an interdisciplinary approach in the reconciliation of chronic medication, medication reconciliation at the time of hospital admission is achieved in $98 \%$ of patients, showing medication errors only in $1.3 \%$ of patients The implementation of EP could improve accuracy, alertness to the potential drug interactions, drug allergies, and time efficiency of service.

The results were satisfying: Performance was $81.82 \%$, Durability was $84.24 \%$, Conformance to specification for pharmacy access right was $93 \%$ while for poly/doctor access right was $86.6 \%$, Feature was $84.24 \%$, reliability was $83.64 \%$, and aesthetic was $79.4 \%$.

The effectiveness score was $80.95 \%$. There were four attributes reaching a maximum score (100\%). It met the user's needs.

However, there were two attributes that did not have optimal effectiveness score. It means that there were still problem, namely the performance attributes (57.14\%) and information (66.67\%). 


\section{DISCUSSION}

Based on the 11 articles reviewed, there were 9 articles that stated that the implementation of e-Prescribing had an effect on reducing Medication Error, facilitating prescription services, speeding up the data input process, and making communication between pharmacists and doctors effective.

There was an article from BMC Health Services Research with the title "The impact of a hospital electronic prescribing and medication administration system on medication administration" with observation as a study design. Observation was conducted at 15 time points before and after the implementation of the Electronic Prescribing and Medication Administration System (EPA). Based on the Pre-EPA on the paper, there were 18 opportunities for drug administration errors in 428 opportunities for error and 18 in 528 with e-PA. Regarding documentation, there were 5 differences in the 460 documentation observed in the pre-EPA on paper, while there were 18 in 557 with EPA. The conclusion of the article was that there were no significant changes after the implementation of the EP, even though it created certain errors and mitigated others (Jheeta and Franklin, 2017).

Meanwhile, another article entitled "Five key recommendations for the implementation of hospital electronic prescribing and medicines administration systems in Scotland" discussed recommendations in implementing E-Prescribing. Since 2016, the National Health Service (NHS) in Scotland has begun implementing electronic prescripttion in hospitals and drug administration systems. There were a number of risks associated with the program. By using the existing experience from other arrangements, it becomes crucial to be informed. There were 5 recommendations included improving coordination between users, modification and flexibility of the Hospital Information Sys- tem, optimizing the system from the beginning, developing expert expertise, disseminating the system, as well as improving learning by experience (Cresswell et al., 2016).

There was also a problem in the implementation of EP, namely acceptance from users (doctors, pharmacists) and the easy use of this system. Based on a Qualitative study entitled "Evaluation of Electronic Prescribing Decision Support System at a Tertiary Care Pediatric Hospital: The User Acceptance Perspective", the pediatricians felt that EPDSS was beneficial. In addition, they showed a good attitude. However, the perception about the easy use and output quality seem to affect the use of EPDSS. Pediatricians generally complained. In addition, they were dissatisfied with the easy use of the EPDS system due to the complicated screen display, the difficulty of seeing and reading the general picture of a patient's medication, the need for many clicks to navigate the system, and not intuitive. In addition, it was difficult to see changes in the prescription which was consisted of information that was not categorized, thus making it difficult to read the prescription (Omar et al., 2017).

Based on the several articles found, the implementation of electronic prescribing could reduce Medication Error, thus affecting patient safety. The evaluation of its implementation was related to the easy use of the system for doctors, nurses and pharmacists. The recommendation is for system flexibility and continuous improvement in the future.

\footnotetext{
REFERENCE

Alfah R, Megariani TVN (2002). Sistem ePrescribing dan Barcode System untuk Resep: 65-76.

Cresswell KM, Slee A, Sheikh A (2016). Five key recommendations for the implementation of hospital electronic prescribing and medicines administration systems in Scotland. Journal Of Inno-
} 
vation In Health Informatics, 23(4).

Farida S, Gede D, Krisnamurti B, Hakim RW, Dwijayanti A, Purwaningsih EH (2017). Implementasi Peresepan Elektronik Implementation of Electronic Prescribing. Implementasi Peresepan Elektronik, 5(3). https://doi.org/10.23886/ejki.5.8834

Hinojosa-Amaya JM, Rodriguez-Garcia FG, Yeverino-Castro SG, Sanchez-Cardenas M, Villarreal-Alarcon MA, Galarza-Delgado DA (2016). Medication errors: electronic vs. paper-based prescribing. Experience at a tertiary care university hospital. Journal of Evaluation in Clinical Practice, 22(5): 751-754. https://doi.org/10.1111/jep.12535

Jheeta S, Franklin BD (2017). The impact of a hospital electronic prescribing and medication administration system on medication administration safety: An observational study. 1-10. https://doi.org/10.1186/s12913-017-2462-2

Mcleod M, Karampatakis GD, Heyligen L, Mcginley A, and Franklin BD (2019). The impact of implementing a hospital electronic prescribing and administration system on clinical pharmacists , activities - a mixed methods study. 4: 112.

Micallef C, Chaudhry NT, Holmes AH, Hopkins S, Benn J, Franklin BD (2017). Secondary use of data from hospital electronic prescribing and pharmacy sys- tems to support the quality and safety of antimicrobial use: A systematic review. Journal of Antimicrobial Chemotherapy, 72(7): 1880-1885. https://doi.org/10.1093/jac/dkxo82

Mills PR, Weidmann AE, Stewart D (2017a). Hospital electronic prescribing system implementation impact on discharge information communication and prescribing errors: a before and after study. European Journal of Clinical Pharmacology, 73(10): 1279-1286. https://doi.org/10.1007/s00228-017-2274-7

Mills PR, Weidmann AE, Stewart D (2017b). Hospital staff views of prescribing and discharge communication before and after electronic prescribing system implementation. International Journal of Clinical Pharmacy, 39(6): 1320-1330. https://doi.org/10.1007/s11096-017o543-2

Omar A, Ellenius J, Lindemalm S (2017). Evaluation of Electronic Prescribing Decision Support System at a Tertiary Care Pediatric Hospital: The User Acceptance Perspective. Studies in Health Technology and Informatics, 234: 256-261.

Villamayor-Blanco L, Herrero-Poch L, DeMiguel-Bouzasy JCM, Freire-Vazquez C (2016). Medicines reconciliation at hospital admission into an electronic prescribing program. Farmacia Hospitalaria, 40(5): 333-340. https://doi.o$\mathrm{rg} / 10.7399 /$ fh.2016.40.5.9080 